\title{
THE WHITE-TAILED DEER
}

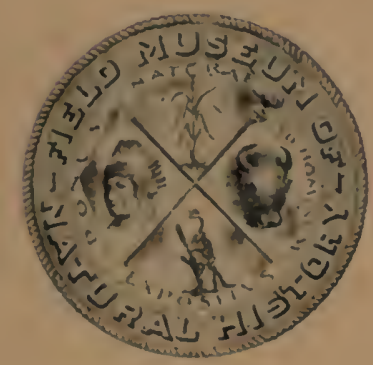

FIELD MUSEUM OF NATURAL HISTORY CHICAGO 




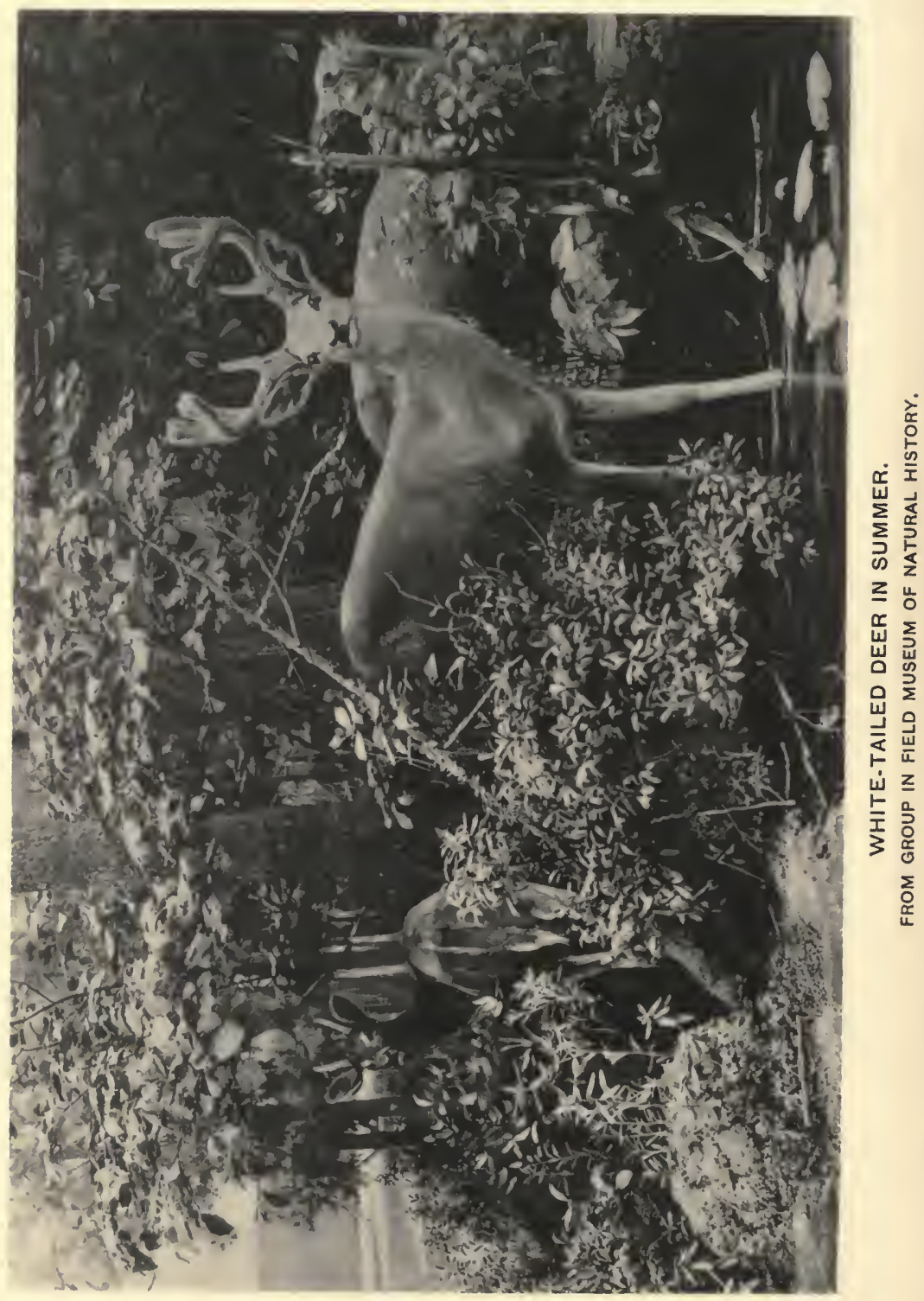


Field Museum of Natural History

DEPARTMENT OF ZOOLOGY

СйсаGo, 1922

\section{The White-Tailed Deer}

The common deer of eastern North America was one of the first of our large mammals to be brought to the attention of early settlers. Although originally abundant in Massachusetts and other parts of New England, it seems to have been reported especially from Virginia by early French writers who called it Cerf de Virginie. It was then given the scientific name Cervus virginianus and so came to be known generally as the Virginia Deer. In later years this name proved to be misleading, for the same species of deer, or varieties differing slightly in size and color, was found to be present not only in Virginia but over most of the eastern and central United States. Another name for it, therefore, has gradually come into use, the name White-tailed Deer. This is frequently shortened to Whitetail, which is a very appropriate name, for the deer's tail is entirely white on the under side and when held erect, as the animal dashes through the woods, is very conspicuous. The upper side of the tail, however, is not white but reddish brown or gray the same as the back and sides of the body.

The White-tailed Deer withstands the advance of civilization much better than most of our larger mammals and is still common over much of its original range. In Pennsylvania, Virginia, and in parts of New York and New England, where elk, bison, bears, couguars and wolves have completely disappeared, the Whitetail still flourishes. This, of course, is mainly on account of the protection afforded by good game laws, 
but it is also due in part to the animal's habits which are very adaptable. It will often maintain itself for years in a small piece of woodland only a few square miles in extent. Its original range included all of eastern North America from the mouth of the St. Lawrence River west to the Rocky Mountains and south to the Gulf of Mexico. Throughout Ohio, Indiana, Illinois and most of Missouri, Kansas and Nebraska, it is now wholly exterminated, but elsewhere it remains common wherever there is sufficient cover for it to exist. Except in the extreme western part of its range it is the only species of deer to be found. In southern Michigan and southern Wisconsin it has retreated before civilization and intensive cultivation of the land, but in the northern parts of these states it is exceedingly abundant. In Illinois, it is probably entirely extinct, although as recently as 1909 it was reported from Union and Alexander counties in the extreme southern part of the state.

The whitetails of the eastern United States are divided into several varieties or subspecies, as follows: The Virginia Whitetail (Odocoileus virginianus), which is of medium size and is now found principally in Virginia, West Virginia and the Carolinas; the Northern Whitetail (Odocoileus $v$. borealis), which is the largest variety and which ranges from Maine and New Brunswick westward at least to Manitoba; the Plains Whitetail (Odocoileus $v$. macrourus), which is said to have an unusually long tail and which formerly inhabited river bottoms throughout the Great Plains region, but is now almost extinct; the Florida Whitetail (Odocoileus $v$. osceola), which is the smallest variety and is confined to Florida; and the Louisiana Whitetail (Odocoileus $v$. louisianae), which is relatively large in size and inhabits the lowlands of Louisiana and eastern Texas. Besides these of the United States 
there are various other whitetails, or closely allied species, inhabiting Mexico, Central America and northern South America. Thus, the whitetails, as a group, have a more extensive distribution than any other American deer.

Perhaps because it is so common and so well known, the Whitetail does not always get full credit for its grace and beauty which are scarcely excelled by any other member of the deer family either in America or in the Old World. No prettier woodland picture ever greets the nature lover's eye than that of our own deer as it threads its way along its forest trail or steps alertly at nightfall from the green depths to the open border of lake or stream. When in motion, especially when not alarmed, it has an ease and grace beyond that of any other of our game animals. Its normal gait is that of running or. trotting and, although it can and does make great leaps, it does not "bound" with all four" feet striking the ground at once as do the western Blacktails or Mule Deer. If slightly startled, it moves away in low, springy jumps alternated at short intervals with single high leaps, the entire movement being characterized by an indescribable grace and resiliency. Meanwhile the head and long, flashing, white tail are held erect and the whole effect as the animal appears and reappears among the trees and bushes makes a beautiful sight.

The outward appearance of the Whitetail shows marked differences with the change of the seasons. In summer its hair is relatively short and thin and the color of its coat is rich reddish rufous. On this account, it has sometimes erroneously been called Red Deer, a name which properly belongs to a very different European species. This red coat is worn during the warm months from May until September in the period when the horns are attaining their annual growth. 


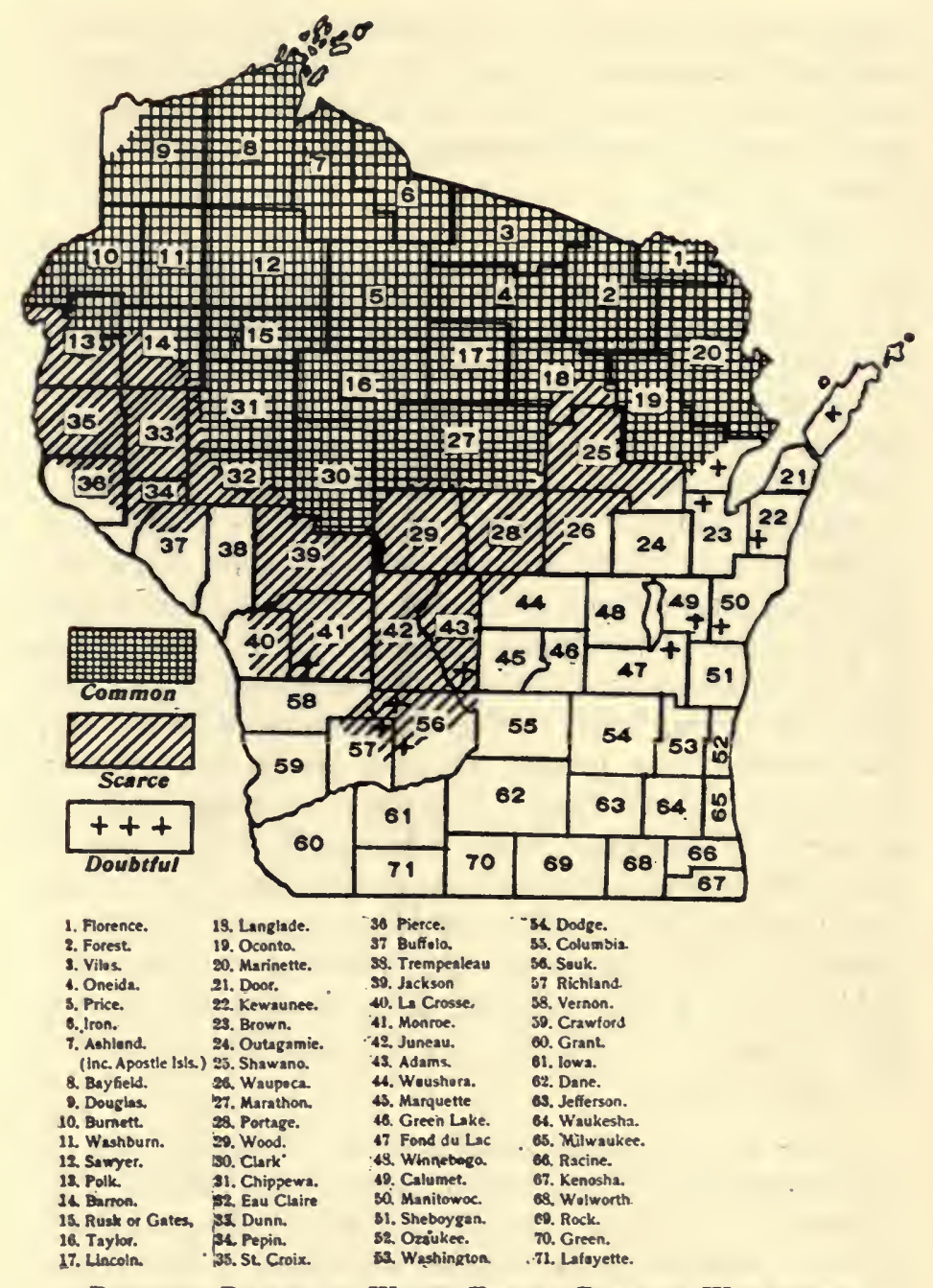

Present Range of White-Tailed Deer in Wisconsin

From Cory's Mammals of Illinois and Wisconsin 
In the fall it is replaced by a beautiful gray coat which gradually grows longer and thicker as cold weather comes on until in midwinter it is full and heavy, forming an ample protection against the severest weather. In spring this coat is more brownish in color and after the long winter is apt to have a ragged and faded appearance, especially just before it is shed and followed by the reddish summer coat. The fawns, which usually are born in May or June, are reddish like the adults at the same season, but are beautifully spotted with white. Late in the fall when the first coat is shed, the fawns lose their spots and become grayish. Two fawns are commonly born at a time and rarely there are three. Young does, as a rule, produce only one fawn and the number varies somewhat in different parts of the country. Male fawns follow their mother for the first year and females often do so for two years.

Like other members of the deer family, the Whitetail sheds and renews its horns annually. The does, or females, never have horns, but the bucks grow a new pair every year. The shedding takes place in late winter or early spring and there is a short period at this time, therefore, when there are no horns in either sex. The mature horns, which are carried through the winter, simply drop off and fall to the ground, leaving only the slight bony knob or pedicel from which they grew. Almost immediately new horns begin to grow, appearing at first as soft prominences covered with the peculiar fuzzy skin which is known as the "velvet." They rapidly elongate and send out branches which are nourished by a copious supply of blood flowing under the protecting velvet. In a few months their growth is practically completed and except for their velvet covering and the club-shaped tips, which harden last, they have much the appearance of mature antlers. Early in the fall, usually in September, the bucks rub their antlers against trees and bushes and the velvet 
comes off in bloody strips and shreds until the fully hardened, smooth horn is exposed and ready for the running and fighting which takes place soon after. The antlers vary in size and form according to the age of the animal. The young buck in his second year has only simple unbranched prongs and therefore is called a "spike" or "spikebuck." In his third year, several additional points are gained but the antlers are relatively small. Full development of the gracefully curved and branched antlers comes in the fourth, fifth, and sixth years when the bucks are in their prime. With advancing years, the antlers may continue of fair size but they are less regular in shape, have fewer points, and are said to be "going back." The normal life of these deer is seldom over ten years.

The habits of the Whitetail vary somewhat according to the region it inhabits, but it always frequents the thickest cover available. In our northern states, it haunts the deep forest, the thickets of alders and willows bordering streams, and the dense growths in swampy flatlands. In summer, like its big cousin, the moose, the Whitetail feeds to some extent on aquatic plants to secure which it wades about shallow coves in lakes and ponds. It does this in broad daylight in remote regions where it is undisturbed, but where man frequently crosses its path, it keeps to cover during the day and only ventures into the open in the darkness of night. It is an excellent swimmer and will voluntarily cross large lakes. When pressed by wolves or dogs it frequently takes to the water. It has even been found swimming in the sea from island to island or point to point on the coast of New England. It makes good time in the water, but unless it has too much of a start can be overtaken by good paddlers with a canoe. Aquatic plants form only part of its food during the summer, for it eats a variety of browse in- 
cluding many tender shoots of small bushes and it is by no means averse to grazing when the marsh grass is abundant.

In the fall, the deer usually move to higher ground and often spend much time in tracts of burnt-over land where the second growth affords good cover. When beechnuts or acorns are available, they feed extensively on them and become very sleek and fat. At this season, the bucks clear their horns of velvet, their necks grow thickened and, as the rutting or mating season approaches, they become restless and roving. The period of the rut extends from late October to early December and is a time of great activity, especially for the bucks, which range far and wide in search of the does. When two bucks meet, a fight is almost a certainty and if they are well matched, the contest may last several hours. They rush together head on and, after locking horns, push each other backward and forward with mouths open and eyes glaring until one or the other acknowledges defeat by leaving the field to his adversary. They seldom gore each other seriously and usually suffer only bruising and temporary exhaustion, but occasionally there are fights to the death. Not infrequently their antlers become inextricably locked and the poor beasts, unable to loose themselves or to take nourishment, struggle to the point of total exhaustion and death. Evidences of these tragedies are found in the weathered skeletons with the bound antlers attached. Probably they are less frequent than might be supposed from the number of sets of locked antlers which are offered for sale by taxidermists and curio dealers, since it is not difficult for the unscrupulous to spring separate antlers into a locked position.

The antlers of the Whitetail may be distinguished from those of other American deer by several characteristics. The two main branches or beams have a 
pronounced forward curve and the points all rise from the back and top of these beams almost perpendicularly. The pair of points nearest the base of the beams are much longer and more upright than in other American deer. The number of points is variable but normally a full grown buck has five or six well-developed points on each side, making ten or twelve in all. Abnormal heads may have several times as many, and in very unusual cases there have been known to be as many as seventy-eight points.

The Whitetail, especially in the northern part of its range, often finds the winter season a great hardship. The deep snows do not prevent it from feeding, for it is able to browse upon twigs and to paw the snow away to secure other food in protected places; but snow interferes greatly with its freedom of movement and makes it an easy prey to its arch enemy, the wolf. When the snow is deep, the deer range within very narrow limits and beat down paths which are followed day after day until a space of several acres may be covered with a network of them. Such places are called "yards" and the deer may congregate in one of them in numbers from two or three to a dozen or more. When forced to leave the yard by dogs or wolves they flounder in the drifts and are easily overtaken. When the snow is slightly hardened on the surface, a form of hunting called "crusting" is sometimes practiced by meat hunters with snowshoes which support them while the deer with their sharp hoofs break through at every leap. Needless to say, crusting is considered quite unsportsmanlike.

Among the different varieties of the Whitetail found in the United States there is much variation in size. The northern variety is much the largest, and full grown bucks from northern New England, Michigan, Wisconsin, and Minnesota will average slightly 
more than 200 pounds live weight. Many have been killed which weighed over 300 pounds and there are some apparently reliable records of bucks weighing as much as 400 pounds. The does are smaller, weighing perhaps 150 pounds for the average. The small Florida Deer weighs scarcely more than half as much as its northern relative and 100 pounds is a good weight for a full grown buck. The maximum for bucks is scarcely more than 125 pounds and does, of course, are much smaller. The Virginia variety is intermediate in size between the northern and the Florida varieties.

The Whitetail has always been a favorite object of the chase. The Indian pursued it before the coming of the white man and made good use of its hide, its horns, and its flesh. The pioneer settler did the same, and buckskin breeches, horn implements, and venison steaks meant almost as much to him as they did to the aborigines. In later years, deer-hunting has furnished fascinating sport for thousands of Americans of all classes in practically every state in the Union. Today it still has innumerable devotees and although the season for shooting is now limited to a few weeks or, in some states, to a few days, there is never any lack of hunters. The methods of deer-hunting vary in different parts of the country, but the most sportsmanlike and at the same time the most difficult type of hunting can be practiced anywhere. This is the so-called still hunting in which the hunter pursues his game by daylight, following its track and using his wits against those of the alert and often crafty wild animal until he is able to approach within shooting distance of it. Such hunting requires great skill in woodcraft, much physical strength, and inexhaustible patience. It is practiced principally when there is light snow on the ground, making the tracks easier to follow, but it can be done by experienced men when there is no snow. 
Where deer are very plentiful, it is possible for the hunter to take up first one trail and then another until fortune favors him and he suddenly comes upon his game and gets at least a running shot as it bounds away. Hounds are used frequently for deer-hunting and most commonly when several hunters station themselves at different points along runways known to be used by the deer, or near lakes to which the deer may take to escape the dogs. In southern states, dogs are sometimes trained as "slow trailers," meaning that they follow a deer's trail without baying and so slowly that the hunter can keep a few yards behind them ready to shoot if the deer is started. Lying in wait at salt licks or favorite feeding places is another method and a much more common one is that of "jacking" or hunting at night with a bright light. Hounding, jacking, killing in the water, night hunting, etc., are now in most states prohibited by law. All such methods may afford some excitement but require little or no skill and if permitted would soon cause the extinction of the deer.

No game animal affords better evidence of the effectiveness of good game laws than the White-tailed Deer. In some of our most populous states it is still abundant, and during the short open season each year thousands are killed by sportsmen. In Vermont, where. it was nearly extinct, and in New Jersey, where it was quite so, it has re-established itself successfully after a period of complete protection. In 1920 , over 4,000 deer were legally killed in Vermont, whereas 25 years ago, scarcely a one could be found. In New York and Pennsylvania it is probable there are more deer now than 50 years ago, although of course they are not so widely distributed. In northern Michigan, Wisconsin and Minnesota, deer are perhaps as abundant as ever they have been. The number of buck deer legally killed 
in New York State in 1918 was 8,293; in Pennsylvania in 1919, it was 2,913; and in Minnesota in 1919, both bucks and does were killed to the tremendous total of 18,572. In 17 states east of the Mississippi River, an estimate of the number of deer killed in 1910 was 60,150. These results have been accomplished by wellconceived and well-administered game laws. At first these merely limited shooting to certain seasons of the year and protected the animals only while the young were being born and partly reared. Later, more restrictions became necessary, such as shortening the season, requiring licenses of hunters, limiting the number permitted to be killed by any one hunter, regulating interstate commerce in game, prohibiting the sale of venison, and wholly prohibiting the killing of does and fawns. The so-called "buck law," by which only males can be legally killed at any season, thus completely protecting the does and fawns, is on the statute books of about half the states and there are fifteen states (including Illinois and Indiana) in which deer hunting is entirely prohibited for a period of years.

Another recent development has been the establishment of both public and private preserves and game refuges. Game farming is also practiced successfully and deer are kept in semi-domesticated conditions in large enclosures and sold under special regulations for their meat or for restocking and propagation purposes. With the good laws now in force and with the demonstrated capacity of the deer to thrive in limited areas in close proximity to man, there is every reason to hope that the White-tailed Deer, perhaps the most attractive of all our game animals, may remain a feature of our woodlands for many years to come.

Wir.Fen H. Oscioon,

Curator of \%oïlogy. 
BOOKS AND ARTICIES ABOUT WHITE-TAILED DEER

Catov, J. D.-Antelope and Deer of America (New York, 1877).

Cory, C. B.-Mammals of Illinois and Wisconsin, pp. 60-66 (Field Museum of Natural History, Pub. No. 153, Zool. Series, Vol. XI, 1912).

Laxtz, D. E.-Deer Farming in the United States, pp. 1-20 (U. S. Dept. Agric., Farmers' Bull., No. 330, 1908).

JY'DEKKER, R.-The Deer of All Lands, pp. 249-267 (London, 1898).

MerriaM, C. H.-Mammals of the Adirondack Region, pp. 107-138 (Trans. Linn. Soc. N. Y., Vol. I, 1884).

Nelsov, E. W.-The Larger North American Manmals, pp. 456-458 (Nat. Geog. Mag., Nov., 1916).

Roosevelt, Theodope-The Deer Family, pp. 65-97 (New York, 1903 ).

Setox, Frnest T.-Life Histories of Northern Animals, Vol. I, pp. 68-113 (New York, 1909).

The White-tailed Deer is especially well shown in the Fielı Museum by a large four-season group in the east end of Hall 16 on the Main Floor. This includes four divisions representing Summer, Autumn, Winter, and Spring. It not only illustrates the deer's habits at different seasons, but shows the changes in its coat throughout the year and the growth and shedding of the antlers. 
